\title{
Arguing with "Libertarianism Without Argument": Critical Rationalism and How it Applies to Libertarianism
}

\section{J. C. Lester}

\section{Introduction}

"Critical-Rationalist Libertarianism"1 (CRL) was replied to in "Libertarianism Without Argument"2 (the reply). Various points in that text are here given responses. Both critical rationalism and how it applies to libertarianism are elucidated and elaborated. This response will proceed by quoting the reply where relevant (virtually all of it) and then responding immediately after the quotations, following the order of the reply's very brief "critique" (605 words).

\section{Quotations and Refutations}

The title of the reply suggests that CRL is advocating "Libertarianism without Argument". Nothing could be further from the truth. Arguments are needed to explain the libertarian ideology and to attempt to rebut any criticisms. But all arguments rest on assumptions. Any attempt to make an argument 'support' some conclusion will entail an infinite regress, or circularity, or dogmatic ('selfevident $^{\text {'3) }}$ starting assumptions. Therefore, arguments cannot provide epistemological support, or justification, for the libertarian conjecture. The common-sense idea that there can be such things as 'supporting arguments' that somehow transcend assumptions - and maybe offer protection from refutation - is not merely false but actually illogical. (One can still, of course, argue 'in favour' of a thesis or be its 'supporter', i.e., advocate it.)

The subtitle of the reply asserts that it "critiques J. C. Lester's argument tha[t] critical rationalism is the basis of libertarianism". There are two significant errors here. First, CRL does notand could not consistently - argue that "critical rationalism is the basis of libertarianism". Rather, it argues that there cannot be any "basis" or foundation: for we cannot escape the realm of conjecture and criticism. People can still have a critically-preferred argument to explain the operation or desirability of libertarianism (liberty in itself, some version of rights, good consequences, human flourishing, a social contract, etc.). And it is a very common error, even among philosophers, to assume that such an argument just is a 'supporting justification' when one happens to agree with it. But no argument can give libertarianism support that is stronger than its own assumptions; and assumptions are no support at all. Nor can it answer, or rule out the possibility of, any unrelated criticisms or refutations of libertarianism. The second significant error is in failing to note that CRL has an abstract theory of liberty that is the central and crucial eleutherology. Critical rationalism is only the epistemology. As such it is relatively peripheral and, in principle, even detachable. ${ }^{4}$

The reply has "two questions ... about how [CRL] applies Popper to libertarianism". Strictly, the issue is about applying the epistemology of critical rationalism to libertarianism. Karl Popper (1902-1994) was not a libertarian, although his epistemology better fits that ideology than he thought (as is explained in Lester $1995^{5}$ ). Popper argued that his epistemology fits liberal democracy.

Of its "two questions", the reply tells us that the "first deals with the system for falsifying theories". Critical rationalism is not a "system": there is no set method of coming up with conjectures

\footnotetext{
1 Lester, J. C. 2012. “Critical-Rationalist Libertarianism.” Libertarianism.org blog (https://www.libertarianism.org/blog/critical-rationalist-libertarianism).

2 Powell, A. R. 2012. "Libertarianism without Argument." Libertarianism.org blog (https://www.libertarianism.org/blog/libertarianism-without-argument).

3 Ambrose Bierce defines "self-evident" as "evident to oneself and no one else" (The Devil's Dictionary).

${ }^{4}$ For a more recent, concise and clear, explanation of both aspects and how they are related, see Lester, J. C. 2022. "Eleutheric Conjectural Libertarianism: a Concise Philosophical Explanation" (PhilPapers: https://philpapers.org/rec/INDNLA)

${ }^{5}$ Lester, J. C. 1995. "Popper's epistemology versus Popper's politics: a libertarian viewpoint". Journal of Social and Evolutionary Systems 18 (1): 87-93 (https://philpapers.org/rec/LESPEV).
} 
or of particular ways to criticise them; and it is not only about "falsifying theories" in empirical ways. Then, "The second is about the strategic value of critical rationalism". If critical rationalism is the true epistemology, and if flouting the true epistemology is not a good strategy, then it cannot be a good strategy to flout critical rationalism. But it is an even better strategy to state that libertarianism is necessarily a conjecture (as are all theories, however well they might have survived tests and criticisms so far), and then invite and attempt to answer any and all criticisms. It cannot be a good strategy to ignore or dismiss people's actual criticisms of libertarianism and, instead, present a putative 'supporting justification' that critics are supposed to study until they agree with it. Unfortunately, that is what - whether tacitly or explicitly - justificationists sometimes do.

There is then the section title, "Can Libertarianism Be Falsified?" Libertarianism is an ideology. Consequently, it has both descriptive (positive or factual) and prescriptive (moral or value) implications. Some parts of the descriptive implications will be empirically testable and thereby falsifiable. Other parts will not but might still not be beyond criticisms of various kinds, and some of these criticisms might amount to falsifications (or refutations). Some parts of the prescriptive implications will be criticisable rather than empirically testable. However, if we can only have a moral obligation to do what it is possible to do (as Kant argued, 'ought' implies 'can'), then a moral implication can be empirically falsified by showing that it is not empirically the case or not possible. So, although you can't derive moral theories from factual theories (as Hume argued, you can't derive an 'ought' from an 'is'), you can sometimes refute moral theories with factual theories (if they are classified as true).

The reply then explicitly reveals the main epistemological confusion behind the "critique":

The basic idea of falsification is that a theory cannot be proved (there could always be some piece of evidence waiting out there that would contradict it) but it can be falsified (a piece of evidence is found that contradicts it).

This is mistaking critical rationalism for falsificationism. The "basic idea" of falsificationism is that a universal scientific theory cannot be in any way supported by finite evidence, but it can and must have possible observable counterexamples. An actual falsification is a true observation-although this remains conjectural - that is inconsistent with a scientific theory. However, empirical falsifiability is only the criterion that Popper offers to distinguish empirical science from what is not empirical science: it explains the necessary and sufficient role of empirical evidence in science. That scientific epistemology was Popper's original insight. By contrast, critical rationalism (as developed by Popper and various other philosophers) extrapolates this scientific epistemology to become a comprehensive epistemology: we can only conjecture and criticise, and all within a framework of conjectures (but one where not everything can be criticised at the same time; some background assumptions are needed). Even mathematics and logic have to use this epistemology. And, consistently, this epistemology is itself a conjecture subject to criticism. (This is unlike falsificationism which, as a philosophical theory, need not apply to itself and be empirically falsifiable.)

The reply continues, "If critical rationalism applies to libertarianism, it must be true, if nothing else, that libertarianism is subject to falsification". If critical rationalism applies to libertarianism, then libertarianism must be a conjecture that is subject to criticism. And it ineluctably is. Some interpretations of libertarianism (such as an a priori Austrian economics version) might be able to rule out empirical falsifications. But they cannot rule out that they have assumptions and that those assumptions might be refuted by criticisms. (Strictly speaking, the assumptions used in Austrian economics are clearly not all necessarily true and they are, in any case, more accurately seen as conjectures that are towards the $a$ priori end of a continuum with a posteriori propositions. ${ }^{6}$ )

The reply then asks, "What would that look like? Does libertarianism make predictions that are subject to falsification?" There are different interpretations of libertarianism. One general interpretation goes as follows. Comprehensive private-property rights-acquired, owned, and

\footnotetext{
${ }^{6}$ For a critical rationalist approach to a priori rationality see Lester, J. C. 2017. Adversus "Adversus Homo Economicus": Critique of the "Critique of Lester's Account of Instrumental Rationality". PhilPapers: https://philpapers.org/rec/LESAAH-2.
} 
transferred with minimised impositions - will strongly tend to avoid externalities: the owner mainly controls any benefits and bears any costs. Consequently, this is the best-known way to protect and promote two very important things at once: interpersonal liberty (people not initiating constraints on each other's preferred outcomes) and economic efficiency (the maximal productivity that benefits one and all). And, of course, all this is seen as desirable and advocated. However much the various libertarian theories differ, this seems to be the key insight —or, at least, presupposition — that is behind them. This general interpretation is both empirically testable and theoretically criticisable in a great manner of ways.

The reply continues,

It's true that free market economics makes predictions. We might say that a policy of protectionism will harm our own economy. If protectionism turns out to not harm the economy, then (that principle of) free market economics is falsified.

There are many empirical implications that might be drawn, and tested, from the free-market economics argument against protectionism. But drawing these implications will involve a lot of theory, and that theory itself will not be beyond criticism. One such criticism is that Austrian economics implies that such an 'empirical test' makes about as much sense as empirically testing whether $2+2=4$. There are also the issues of what constitutes "harm", "our own economy", and whether it is even an "economy" as it is not an organisation (but a catallaxy, as Hayek called it), and so on. The general point is that some theoretical interpretations will allow for empirical tests, but no interpretation can escape criticism; and either approach might be sufficient to achieve an apparent refutation.

The reply rightly recognises that

Popper fully admits that, given the fallibility of humans and the instruments they use to examine evidence, we probably shouldn't toss out a theory based on a single piece of contradictory evidence. After all, the evidence might be bad. We might have read our meter wrong. And so on. We shouldn't give up on a theory too easily, in other words.

This is no more than consistent, of course. If it is useful to have empirical tests, then it is useful to test our tests as well. It only needs to be added that some tests might sometimes be better dealt with by theoretical criticisms (whether from the realm of economics, philosophy, game theory, or whatever). And that is broader than empirical falsificationism but it is still part of critical rationalism.

The reply espies a potential problem:

The trouble might be, however, that this wiggle room proves too much — that, when we're talking about theories like libertarianism or socialism or free market economics or protectionism, there's just no way to come up with the kind of evidence needed to pronounce something false.

It is entailed by critical rationalism that we can never apodictically "pronounce something false". We never know what error, evidence, conjecture, or criticism we may have overlooked. However, we can consistently classify something as false given the current state of the critical debate. And some refutations will be impressively clear and cogent. With Marxian socialism ${ }^{7}$ the economic-calculation problem, ${ }^{8}$ which is more theoretical than empirical, does appear to be just one such clear and cogent refutation (or, at least, an ineluctable problem). With libertarianism, etc., there is no end of possible ways that either an empirical or theoretical refutation might be possible. One obvious empirical way is to compare the effects of some aspect of libertarianism (such as drug liberalisation, or private roads, or education without the state) where there are before-and-after consequences in the same country, or where this occurs in some countries but not others. It only needs one genuine counterexample to

\footnotetext{
${ }^{7}$ Marxian socialism entails the abolition of money and markets in favour of some alternative, and superior, way of allocating resources.

${ }^{8}$ Monetary pricing is the only known way of determining relative scarcity in a mass market. We need to know relative scarcity if we are to perform economic calculations and allocate resources efficiently.
} 
refute the universal theory that libertarianism is preferable to state-intervention (but an apparent counterexample may really be the result of other state-interventions: we have to test the test).

But, as with Marxian socialism, there are possible refutations that draw on theory too. If some economic theory could convincingly explain how markets are inherently unstable-with intrinsic booms and busts - and how governments can have superior knowledge, benign motives, and are able to intervene without doing more harm than good, then that would refute libertarianism (in its universal form, at least: we still might be better off with as much libertarianism as is possible). Such theories have been tried but found wanting, or so libertarians argue. Nevertheless, in principle, empirical or theoretical matters might produce an apparent refutation just as impressive as the economic calculation problem for Marxian socialism. In the meantime, the big picture-as we look across the world and back through history - is that people are freer and more thriving to the extent that they are subjected to less political intervention.

The reply gives this example:

Take the stimulus. Clearly the impact of it counts as evidence against economic theories. But evidence of what? And against which theories? Paul Krugman might argue that the stimulus failed to spark the kind of growth we hoped because it wasn't big enough - and had it been smaller, we'd be in much worse shape than we are. My Cato colleagues, on the other hand, might argue that the stimulus never could've worked in the first place, and so it was, by definition, too big. Furthermore, each side is perfectly capable of modifying their underlying theories to allow even fully interpretable evidence. Maybe there was something really special about this particular time for stimulus that made it not work when it otherwise would, or work when it otherwise wouldn't.

This appears, in effect, to be a criticism of the principle that we ought to try to refute theories; whether with empirical evidence, or theoretical arguments, or both. Is it really always the case that "each side is perfectly capable of modifying their underlying theories to allow even fully interpretable evidence"? Even if so, this either implies that the theories have been partially refuted, for they are "modifying their underlying theories" (unless this means theories additional to the disputed one), or it implies that we can be stuck in incommensurable theories and that any argument is a waste of time (which is at odds with the implied criticism of the reply's own title). It seems more useful and accurate to say that we need to try harder to make any refutation more obvious. After all, some people are argued out of stimulus positions (and some people are argued into them as well: perhaps they did not start with a clear grasp of free-market economics). Critical rationalism does not imply that all refutations are going to be easy, obvious, or universally convincing. In any case, the only alternatives to attempted refutations are dogmatism and coercion: the dysfunctional opposites of reason and science.

The reply then moves onto philosophy itself:

These sorts of questions become even more difficult to deal with when we're talking about abstract political philosophy ideas like liberty or equality. If I adopt a high liberal position, for instance, and do so because I value equality over liberty, what sort of evidence might prove me wrong?

This is using "liberal" in the modern, but particularly US, sense. All kinds of empirical evidence and theoretical criticisms are potential refutations: it partly depends on the various background assumptions - empirical, theoretical, moral, etc. - of the advocate. For instance, empirical evidence and economic theory might be explained to show that politically-imposed movements towards equality eventually make the poorest people poorer than they would otherwise have been (by undermining economic calculation) or maintain poverty that would otherwise disappear in a generation or so. Does the advocate still want political attempts at equality if that is the case? That said, economic theory also explains how free markets have a systemic tendency towards equality to the extent that it is economically efficient: all above-average profits or wages will attract competition that erodes any differences as far as this is practical. Or a philosophical argument might explain how equality has no inherent value and that we should be more concerned with helping the worst-off people irrespective of whether that increases inequality. As stated, exactly what would refute an advocate of equality will depend on the specific advocate. It is a strength of critical rationalism that it 
addresses his particular assumptions, arguments, and criticisms. Presenting a necessarily spurious 'supporting justification' of libertarianism would likely leave such an advocate completely unmoved.

The very section heading "Spreading Liberty without Arguments" suggests what is a practical impossibility. How could an ideology be promoted without using arguments? Some ideologies might use aggressive coercion as well: ultimately, all political ideologies do, or aspire to do so. But even they will need to offer some conjectural arguments about what they are trying to achieve and why. Otherwise, people would see the unexplained aggressive coercion but remain unchallenged and unchanged in their existing ideologies. The heading's implication, of course, is that critical-rationalist libertarians are "without arguments". But, as we have seen, to abandon 'supporting arguments' is not to abandon arguments. In fact, critical rationalists are likely to engage in more arguments: both in terms of many different explanations and in defence against all criticisms. The archetypal justificationist is more likely to stick to his one preferred 'justificatory argument' and dogmatically dismiss criticisms.

The reply asks

what motivates non-libertarians to listen? It seems at least plausibly rational for high liberals, communitarians, or conservatives to say, "Sure I haven't disproved your theory, but you haven't given me any reason to believe it, either."

This appears to suggest that critical-rationalist libertarians can do no more than pose libertarianism as a simply-stated conjecture. Of course, we will not attempt to offer "any [supporting] reason to believe it". But we can offer conjectural explanations - empirical and theoretical —of both what we think is right about libertarianism and what we think is wrong about our opponents' non-libertarian alternatives, and then invite the non-libertarians to respond. Failing this, we would not be applying critical rationalism. It is no impediment that we admit that libertarianism cannot transcend being a conjecture, and that our criticisms of the opposing ideology are not asserted to be beyond doubt. On the contrary, this undogmatic approach is more likely to encourage a response.

The reply attempts to recast its question thus:

Put another way, does critical rationalist libertarianism rely upon libertarianism being the default position within political philosophy, one that must be proved wrong before we're justified in believing anything else?

Whether or not this is an equivalent question, it is easily answered. First, critical-rationalist libertarianism does not "rely" on anything: all is conjecture and open to criticism (including critical rationalism itself). Perhaps the "default position within political philosophy" is somewhere in the middle of the Overton window or 'window of discourse' (politically acceptable ideas given current public opinion). Libertarianism is a bold conjecture and, as such, can hardly be the "default position". But it can still be conjecturally explained in various ways. And it remains an unrefuted conjecture-or so libertarians assert - unless and until a refutation can be found. In these respects, it is just like all the other 'political' ideologies (although critical-rationalist libertarians would argue that refutations have been found for them). We are, of course, never "justified in believing anything else" in the sense that our beliefs, or theories, are supported. However, one could still claim to have "justified" an ideology in a completely different sense: one has 'squared' it (i.e., made it fit, or reconciled it) with all the currently known tests and criticisms: by passing or withstanding them, or by faulting them. But that only amounts to an assertion that it has escaped attempted refutation so far. It is no kind of support, basis, or foundation in an epistemological sense. It would be clearer to call that a critically-preferred conjecture. ${ }^{9}$

(November 2017; revised January 2022.)

\footnotetext{
${ }^{9}$ This response has benefitted the critical input of Mark Brady, David McDonagh, and Ray Percival.
} 